\title{
EDUCATIONAL INEQUALITIES IN REPEAT ABORTION: A LONGITUDINAL REGISTER STUDY IN FINLAND 1975-2010
}

\author{
HEINI VÄISÄNEN ${ }^{1}$ \\ Department of Social Policy, London School of Economics and Political Science, UK
}

\begin{abstract}
Summary. The proportion of repeat abortions among all abortions has increased over the last decades in Finland. This study examined the association of education with the likelihood of repeat abortion, and the change in this association over time using reliable longitudinal data. A unique set of register data from three birth cohorts were followed from age 20 to 45 , including about 22,000 cases of repeat abortion, and analysed using discretetime event-history models. Low education was found to be associated with a higher likelihood of repeat abortion. Women with low education had abortions sooner after the preceding abortion, and were more often single, younger and had larger families at the time of abortion than more highly educated women. The educational differences were more significant for later than earlier cohorts. The results show a lack of appropriate contraceptive use, possibly due to lack of knowledge of, or access to, services. There is a need to improve access to family planning services, and contraceptives should be provided free of charge. Register data overcome the common problems of under-reporting of abortion and attrition ensuring the results are reliable, unique and of interest internationally.
\end{abstract}

\section{Introduction}

The overall abortion rate in Finland is relatively low (about 9/1000 fertile age women since the 1990s), but the proportion of repeat induced abortions among all abortions has increased in the last three decades, from approximately $30 \%$ to $40 \%$ (Heino et al., 2011), even though Finland provides family planning services in all municipalities (Hemminki et al., 1997; Kosunen, 2000), compulsory sex education at school (Kontula, 2010), contraceptive counselling after an abortion (Levels et al., 2014) and financial and other support for families lowering the costs of childbearing (Vikat, 2004). Abortions have been allowed for socioeconomic reasons since 1970 (Knudsen et al., 2003). Few studies have examined whether the increase in repeat abortion has occurred evenly between socioeconomic groups, although such studies would help create interventions

\footnotetext{
${ }^{1}$ Email: h.e.vaisanen@1se.ac.uk
} 
aimed at avoiding such procedures. Avoiding unintended pregnancy would reduce public expenditures compared with the cost of repeat abortion (Cleland et al., 2011; Frost et al., 2014).

Previous studies on the association between repeat abortion and socioeconomic position have been inconclusive. Cross-sectional studies have identified a positive association between low education and repeat abortion in the US (Jones et al., 2006), UK (Stone \& Ingham, 2011) and Sweden (Makenzius et al., 2011), but not in Denmark (Osler et al., 1997). However, apart from one study (Jones et al., 2006), sample sizes were small $(N=150-798)$. Longitudinal studies using Finnish register data collected in the early 2000s, following women for up to 8 years, suggested that having a low socioeconomic position was associated with increased likelihood of repeat abortion (Niinimäki et al., 2009; Väisänen \& Jokela, 2010; Mentula et al., 2010). None of these studies compared cohort trends or educational differences. Other characteristics commonly associated with higher incidence of repeat abortion include having children (Osler et al., 1997; Jones et al., 2006; Heikinheimo et al., 2008; Niinimäki et al., 2009; Väisänen \& Jokela, 2010; Makenzius et al., 2011; Stone \& Ingham, 2011; Rose et al., 2015), being unemployed (Das et al., 2009), not being married (Jones et al., 2006; Niinimäki et al., 2009; Väisänen \& Jokela, 2010) and using barrier (Osler et al., 1997; Niinimäki et al., 2009) or oral contraceptives (Jones et al., 2006; Heikinheimo et al., 2008; Niinimäki et al., 2009) rather than long-acting reversible methods of contraception.

The aim of this study was to examine whether there is an educational gradient in the occurrence of repeat abortion, whether the association has changed over time, and how the educational differences vary by time since previous abortion, parity, relationship status and age using unique and nationally representative longitudinal data based on Finnish administrative registers. These data overcome the problem of under-reporting of abortions in surveys (Gissler et al., 1996; Jones \& Kost, 2007). The analysis covers the years 19752010, which is a longer period of time and larger-scale comparison than in any other previous study of repeat abortion, and uses population-level data including women who have already completed their childbearing, which is rare (see e.g. Rose et al., 2015). Given how difficult it usually is to study this topic using large-scale high-quality data, the results are of interest internationally.

\section{Methods}

\section{Data and sampling}

Nationally representative data on three female cohorts (born in 1955-59, 1965-69 and 1975-79) collected from the Registry of Induced Abortions, the Medical Birth Registry and the Population Registry of Finland were used. Not all women were included, because ethics regulations in Statistics Finland do not allow for using complete populations for research purposes. First, an $80 \%$ random sample of all women in the above cohorts, who had had at least one abortion within the study period (i.e. ages 15-50 or before the year 2010), were collected $(N=91,636)$. Second, a comparison group, twice the size of the study group, of women from the same cohorts who had not had an abortion in Finland, were selected using random sampling $(N=183,272)$. The sample was taken from the group of women who had lived in Finland for at least a year within any of the periods $1970-75,1980-85$ or $1987-2010$, because these were the years when 
detailed information on the Finnish population was available. Weights were used to control for this design in the statistical analysis. The unweighted sample included almost half of the Finnish women in these cohorts; the amount of missing information was minimal (see Väisänen (2015) and Väisänen and Murphy (2014) for more information regarding the dataset).

\section{Variables}

The outcome variable was the occurrence of a second or third abortion within an individual's fertile life span. Only second and third abortions were analysed, because there were too few higher-order abortions to conduct a reliable analysis (less than $2 \%$ of abortions).

The main explanatory variable is education, categorized as low (only completed the compulsory 9 years of schooling); middle (at least upper secondary education); and high (tertiary) education. It was assumed that someone had at most compulsory education if there was no education level recorded in the dataset, because Statistics Finland does not give information for research purposes about people with less than upper secondary education due to ethical regulations. The other variables included in the analyses were time since previous abortion, parity, age, relationship status, place of residence (province and level of urbanization) and nativity (native Finn vs non-native), because previous studies have found these characteristics to be associated with repeat abortion (Osler et al., 1997; Jones et al., 2006; Heikinheimo et al., 2008; Niinimäki et al., 2009; Väisänen \& Jokela, 2010; Makenzius et al., 2011).

The dataset included year and month of all abortions and live births; changes in relationship status were updated annually; education and place of residence were measured at ages 20,25 and 30 or the nearest year possible, because these variables were recorded in the population register only every five years (1970, 1975 etc.) until the year 1987, after which the variables have been updated annually. These variables vary in time in the statistical models. Since information on cohabitation was not included in the registers before 1987, cohabiting women were classified as single in the 1950s cohort. Because there were only a few widowed women, they were grouped together with divorced women in all cohorts. There were not many women in the dataset who had high education at the time of their third abortion $(N=36-47$, depending on cohort). Thus, in the multivariate analysis of third abortions these women were combined with the middle education group.

\section{Statistical analysis}

All analyses were conducted for women aged 20 or more, because there was no variation in education before that age, and because few repeat abortions in the sample were obtained before age 20 (5-7\% depending on cohort). Women were censored aged 45 , in the year 2010 or at time of death or emigration, whichever came first.

Probability of ever having an abortion (as well as having at least two and three) was calculated by dividing the number of women who ever had an abortion by the number of all women in each cohort and educational group, both appropriately weighted. The probability of progressing onto one's second (third) abortion among 
those who had already had one (two) abortion was calculated by dividing the number of women who had had at least two (three) abortions by the number of women who had had at least one (two). In this analysis the number of abortions and level of education were measured when the women were aged 45, in the year 2010, or at time of death or emigration, whichever came first. The estimates of the gap between educational groups are thus more conservative than if education was measured at the time of abortion, because some women may have obtained more education after the event. Next, the mean number of children, mean age, proportion married and median duration since previous abortion (when appropriate) at the time of first, second and third abortion were calculated separately for each educational group and cohort.

Discrete-time event-history models with years since previous abortion as the exposure time were constructed separately for the likelihood of second and third abortion. The former models only included women who had had at least one abortion and the latter only women who had at least two abortions. All models were constructed separately for second and third abortions, education and cohort because some of the explanatory variables may be differently associated with the outcome depending on an individual's education, cohort and order of abortion. First, each covariate was regressed with the outcome alone, after which fully adjusted models were conducted. A logistic multilevel model of recurrent events nested within individuals including all women was conducted to test whether the likelihood of progressing onto the next abortion was dependent on unobserved individual characteristics, but no such dependency was found. Thus, the simpler single-level model was chosen.

Educational differences in second and third abortions by time since previous abortion were calculated using average marginal effects at representative values (Williams, 2012). These probabilities were calculated, because it is relevant for policymakers to know how the absolute risk varies after the initial abortion in order to plan appropriate interventions.

In the 1970s cohort, the youngest women only reach age 31 by the end of the study period, whereas in the other cohorts even the youngest women reach age 41 , which may compromise the comparability of the results between cohorts. Therefore sensitivity analyses were conducted for women aged 31 or younger for the two earliest cohorts (results reported briefly in text in Results section). All analyses were conducted in Stata version 13.

\section{Results}

Table 1 shows selected characteristics of the women in the study by level of education. Women with low education more often were non-native Finns, had higher average number of abortions, marginally higher mean parity and markedly lower income than women with high education. Education is thus an indicator of the socioeconomic position of these women and is also associated with other socio-demographic characteristics of interest. The table also shows that the proportion of women with low education decreased over time: $26 \%$ of women in the earliest cohort had low education, compared to $13 \%$ in the latest cohort.

Overall 22, 23 and 15\% of all women ever had an abortion, and 5, 6 and 4\% at least two abortions in the 1950s, 1960s and 1970s cohorts, respectively (results not shown). A quarter of women with low education in the 1950 s cohort, over $40 \%$ in the 1960 s cohort and almost a third in the 1970s cohort had at least one abortion, whereas only 
Table 1. Selected socio-demographic characteristics of women when they were last observed in the study (i.e. at age 45 , year 2010 , or at time of death or emigration) by education and cohort (weighted $\%$ and weighted $n$ )

\begin{tabular}{lrrrrr}
\hline & \multicolumn{3}{c}{ Education } & & \\
\cline { 2 - 4 } & Low & Middle & High & Total \% & Weighted $n$ \\
\hline Cohort 1955-59 & 26.0 & 64.0 & 10.0 & 100 & 104,455 \\
Native Finn & 24.0 & 65.9 & 10.2 & 100 & 100,596 \\
Non-native Finn & 87.6 & 10.6 & 1.8 & 100 & 3859 \\
Mean parity & 1.82 & 1.88 & 1.76 & & \\
Mean abortions & 0.36 & 0.28 & 0.16 & & \\
Mean annual income $(€)$ & 8167 & 9812 & 15,251 & & \\
Cohort 1965-69 & 18.4 & 67.1 & 14.6 & 100 & 93,130 \\
Native Finn & 13.9 & 70.8 & 15.3 & 100 & 7706 \\
Non-native Finn & 72.1 & 21.5 & 6.5 & 100 & \\
Mean parity & 1.82 & 1.81 & 1.76 & & 61,633 \\
Mean abortions & 0.51 & 0.31 & 0.14 & & 65,413 \\
Mean annual income $(€)$ & 10,615 & 13,855 & 20,578 & & \\
Cohort 1975-79 & 13.1 & 46.9 & 40.0 & 100 & 100 \\
Native Finn & 8.5 & 49.2 & 42.4 & 100 & \\
Non-native Finn & 54.6 & 26.7 & 18.6 & 100 \\
Mean parity & 1.44 & 1.40 & 1.13 & & \\
Mean abortions & 0.39 & 0.25 & 0.10 & & \\
Mean annual income $(€)$ & 12,740 & 18,292 & 26,366 & & \\
\hline
\end{tabular}

Estimates were calculated for all women, i.e. included women who never had an abortion (see Väisänen \& Murphy (2014) or Väisänen (2015) for more information about the dataset). Education was measured at age 30 (or the nearest year possible) and it was assumed that women had received their highest level of education by that age. Income was also last measured at age 30 and it refers to an individual's annual taxable income. Parity was measured when the women were last observed in the data, i.e. in the year 2010, age 45 or at the time of death or emigration. Non-native Finn refers to women who were not born in Finland and/or whose native language was not Finnish or Swedish.

9-14\% of women with high education ever had an abortion, depending on cohort (Table 2). Although $7-17 \%$ of women with low education (depending on cohort) had a second abortion, only $1-2 \%$ of highly educated women did so. The trends for third abortions were quite similar.

Women who had already had one abortion had from $26 \%$ (in the 1950 s cohort) to $38 \%$ probability (in the other cohorts) of progressing to a second abortion if they had low education, whereas highly educated women had only $12-15 \%$ probability of doing so (depending on the cohort). The probabilities of progressing onto a third abortion were similar (Table 2). The differentials between educational groups were more marked for the later than the earlier cohorts.

Among all women the median duration since previous abortion at the time of second abortion was 56, 65 and 45 months in the 1950s, 1960s and 1970s cohorts, respectively, 46 months in the earliest two cohorts and 30 months in the latest cohort at the time of 
Table 2. Probability of having at least one, two or three abortions within the study period and abortion progression ratios by cohort and education (weighted $\%$ and unweighted $n$ )

\begin{tabular}{llrrrr}
\hline & & & & \multicolumn{2}{c}{ Education } \\
\cline { 3 - 5 } & & $n$ & Low & Middle & High \\
\hline Cohort 1955-59 & Ever had an abortion & 35,891 & 26.4 & 22.0 & 13.5 \\
& Ever had second abortion & 8031 & 7.0 & 4.7 & 1.9 \\
& Ever had third abortion & 1985 & 1.9 & 1.1 & 0.3 \\
& Probability of progression to 2nd abortion & & 26.4 & 21.2 & 14.3 \\
& Probability of progression to 3rd abortion & 27.6 & 23.5 & 16.6 \\
Cohort 1965-69 & Ever had an abortion & 34,416 & 45.4 & 30.1 & 13.8 \\
& Ever had second abortion & 9389 & 17.1 & 7.5 & 2.1 \\
& Ever had third abortion & 2935 & 6.8 & 2.1 & 0.4 \\
& Probability of progression to 2nd abortion & & 37.6 & 24.3 & 12.4 \\
& Probability of progression to 3rd abortion & & 40.4 & 28.6 & 18.6 \\
& Ever had an abortion & 20,774 & 31.3 & 22.5 & 9.1 \\
& Ever had second abortion & 5079 & 11.8 & 5.5 & 1.1 \\
& Ever had third abortion & 1587 & 4.8 & 1.6 & 0.2 \\
& Probability of progression to 2nd abortion & & 37.7 & 24.8 & 14.9 \\
& Probability of progression to 3rd abortion & & 39.4 & 27.5 & 18.7 \\
\hline
\end{tabular}

the third abortion (results not shown). The duration varied largely by education. For instance, half of women with low education in the 1950-60s cohorts had their second abortion within about 5 years of the first one compared with 8 or 9 years among those with high education. The median durations since previous abortion were shorter for the 1970s cohort due to shorter exposure time, but educational differences were marked, and followed the same pattern as in the other cohorts (Table 3).

On average, women had higher parity at the time of second and third abortions compared with first abortions, but the relationship varied by education: women with low education had higher parity at the time of abortion than women with at least middlelevel education. In the 1950s and 1960s cohorts, about half of the women with high education were married at the time of their first and second abortions, compared with $24-34 \%$ of women with low education. Around a third of women were married at the time of their first and second abortions in the 1970s cohort compared with a fifth of women with low education. Women were on average older at the time of second and third abortions than at their first abortions, and similarly women with high education were older than women with low education, as one would expect (Table 3).

Selected odds ratios of the multivariate analysis are shown in Table 4 (full results available on request). The crude odds ratios (not shown) were similar to the adjusted ones, apart from parity, for which the effect often reversed after controlling for age, mainly because the likelihood of abortion declines by age and childless women are typically younger than women with children.

Table 4 shows that the likelihood of second abortion was positively associated with higher parity in all cohorts among women with lower and middle-level education. 
Table 3. Sample characteristics at the time of first, second and third abortion (weighted $\%$, medians and means; unweighted $n$ )

\begin{tabular}{|c|c|c|c|c|c|c|c|}
\hline & & Education & $n$ & $\begin{array}{l}\text { Median time since } \\
\text { previous abortion } \\
\text { (months) }\end{array}$ & $\begin{array}{l}\text { Mean } \\
\text { parity }\end{array}$ & $\begin{array}{c}\% \\
\text { Married }\end{array}$ & $\begin{array}{c}\text { Mean } \\
\text { age }\end{array}$ \\
\hline \multirow[t]{9}{*}{ First abortions } & \multirow[t]{3}{*}{ Cohort 1955-59 } & Low & 9718 & & 1.05 & 32.7 & 26.7 \\
\hline & & Middle & 12,543 & & 1.03 & 35.0 & 29.1 \\
\hline & & High & 1015 & & 1.24 & 54.1 & 34.2 \\
\hline & \multirow{3}{*}{ Cohort 1965-69 } & Low & 7172 & & 1.06 & 27.8 & 26.5 \\
\hline & & Middle & 16,126 & & 0.80 & 23.7 & 27.7 \\
\hline & & High & 1130 & & 1.24 & 52.7 & 34.4 \\
\hline & \multirow[t]{3}{*}{ Cohort 1975-79 } & Low & 4410 & & 0.89 & 21.5 & 24.3 \\
\hline & & Middle & 9272 & & 0.53 & 13.9 & 24.8 \\
\hline & & High & 1245 & & 0.66 & 36.5 & 29.1 \\
\hline \multirow{9}{*}{ Second abortions } & \multirow{3}{*}{ Cohort 1955-59 } & Low & 3196 & 56 & 1.39 & 33.9 & 28.6 \\
\hline & & Middle & 3835 & 75 & 1.30 & 34.5 & 31.1 \\
\hline & & High & 212 & 105.5 & 1.26 & 47.6 & 34.6 \\
\hline & \multirow[t]{3}{*}{ Cohort 1965-69 } & Low & 3358 & 56 & 1.38 & 24.4 & 27.8 \\
\hline & & Middle & 5050 & 70 & 1.15 & 24.5 & 29.9 \\
\hline & & High & 250 & 98.5 & 1.34 & 50.5 & 35.1 \\
\hline & \multirow[t]{3}{*}{ Cohort 1975-79 } & Low & 2011 & 38 & 1.18 & 18.6 & 25.0 \\
\hline & & Middle & 2467 & 50 & 0.94 & 18.1 & 26.6 \\
\hline & & High & 233 & 54 & 0.89 & 34.1 & 29.6 \\
\hline \multirow[t]{9}{*}{ Third abortions } & \multirow[t]{3}{*}{ Cohort 1955-59 } & Low & 892 & 39.5 & 1.63 & 32.6 & 30.4 \\
\hline & & Middle & 991 & 52 & 1.50 & 32.5 & 32.8 \\
\hline & & High & 36 & 73.5 & 1.09 & 30.3 & 36.6 \\
\hline & \multirow{3}{*}{ Cohort 1965-69 } & Low & 1347 & 42 & 1.66 & 23.6 & 29.6 \\
\hline & & Middle & 1497 & 50 & 1.41 & 23.7 & 31.8 \\
\hline & & High & 47 & 43 & 1.26 & 35.9 & 35.6 \\
\hline & \multirow{3}{*}{ Cohort 1975-79 } & Low & 804 & 30 & 1.46 & 17.5 & 26.3 \\
\hline & & Middle & 709 & 30 & 1.18 & 17.1 & 27.7 \\
\hline & & High & 46 & 40 & 1.06 & 24.5 & 30.2 \\
\hline
\end{tabular}

For instance, women with low education who had at least three children had around 2.5 times the odds of second abortion compared with otherwise similar women without children. Parity was not associated with the likelihood of second abortion among highly educated women in the 1950s and 1960s cohorts, but in the 1970s, cohort women with three children and high education had 3.4 times the odds of abortion compared with childless women at that level of education. High parity was associated with a higher likelihood of a third abortion too, but the educational differences were smaller, particularly in the 1950s and 1960s cohorts (Table 4).

Single, divorced or widowed women had a higher likelihood of second abortion than married women in all cohorts. Although these differences were marked for women with low education, they were small for women with high education in the 1950s and 1960s cohorts. There was a negative association with age and the likelihood of second abortion among low educated women, but age was not associated with it among women with high education in the first two cohorts and had only a weak negative association in the 1970s cohort (Table 4).

The predicted probabilities in Fig. 1 show that time since previous abortion was not strongly associated with the likelihood of second abortion among women with high education. Among women with low education the risk of second and third abortions peaked typically within a year or two after the previous abortion. The educational gap was markedly wider for later than earlier cohorts and the absolute level of risk was much 
Table 4. Selected odds ratios (OR) of second and third abortions by cohort

\begin{tabular}{|c|c|c|c|c|c|c|c|}
\hline & & \multicolumn{2}{|c|}{ Cohort 1955-59 } & \multicolumn{2}{|c|}{ Cohort 1965-69 } & \multicolumn{2}{|c|}{ Cohort 1975-79 } \\
\hline & & Low education & High education & Low education & High education & Low education & High education \\
\hline Second abortions & & $\mathrm{OR}^{\mathrm{ab}}$ & $\mathrm{OR}^{\mathrm{ab}}$ & $\mathrm{OR}^{\mathrm{ab}}$ & $\mathrm{OR}^{\mathrm{ab}}$ & $\mathrm{OR}^{\mathrm{ab}}$ & $\mathrm{OR}^{\mathrm{ab}}$ \\
\hline \multirow[t]{6}{*}{ Time since last abortion } & $<6$ months & 1.00 & 1.00 & 1.00 & 1.00 & 1.00 & 1.00 \\
\hline & 6-12 months & 1.19 & 1.07 & $3.07 * * *$ & 1.35 & $2.46^{* * *}$ & 1.40 \\
\hline & $1-2$ years & $1.40^{* *}$ & 1.10 & $3.31 * * *$ & 1.28 & $1.63^{* * *}$ & 0.72 \\
\hline & $2-4$ years & 1.12 & 0.86 & $2.97 * * *$ & 1.07 & $1.34 *$ & 0.79 \\
\hline & 4-6 years & 0.83 & 0.93 & $2.34 * * *$ & 0.62 & 0.99 & 0.56 \\
\hline & $\geq 6$ years & $0.55^{* * *}$ & 0.66 & $1.69 * *$ & 0.68 & $0.67 * *$ & $0.33 * * *$ \\
\hline \multirow[t]{4}{*}{ Parity } & No children & 1.00 & 1.00 & 1.00 & 1.00 & 1.00 & 1.00 \\
\hline & 1 & $1.48^{* * *}$ & 1.08 & $1.72 * * *$ & 0.99 & $1.64 * * *$ & $1.87 * * *$ \\
\hline & 2 & $2.09 * * *$ & 1.15 & $2.12 * * *$ & 1.21 & $1.86^{* * *}$ & $2.24 * * *$ \\
\hline & $\geq 3$ & $2.63^{* * *}$ & 1.39 & $2.75^{* * *}$ & 1.56 & $2.48^{* * *}$ & $3.44 * * *$ \\
\hline \multirow[t]{4}{*}{ Union status } & Single & 1.00 & 1.00 & 1.00 & 1.00 & 1.00 & 1.00 \\
\hline & Married & $0.58^{* * *}$ & $0.60^{* *}$ & $0.43 * * *$ & $0.63^{*}$ & $0.51^{* * *}$ & $0.32 * * *$ \\
\hline & Cohabiting & na & na & $0.56 * * *$ & 0.86 & $0.62^{* * *}$ & $0.36^{* * *}$ \\
\hline & Divorced & $1.16^{*}$ & 1.50 & $0.87^{*}$ & 1.02 & 0.83 & 0.61 \\
\hline \multirow[t]{6}{*}{ Age } & $20-24$ & 1.00 & 1.00 & 1.00 & na & 1.00 & na \\
\hline & $25-29$ & $0.88^{*}$ & 1.81 & $0.85^{* *}$ & 1.00 & 0.95 & 1.00 \\
\hline & $30-34$ & $0.76^{* * *}$ & 2.26 & $0.60^{* * *}$ & 1.53 & $0.49^{* * *}$ & $0.72 *$ \\
\hline & $35-39$ & $0.39^{* * *}$ & 1.94 & $0.35^{* * *}$ & 1.51 & na & na \\
\hline & $40+$ & $0.18^{* * *}$ & 0.80 & $0.090^{* * *}$ & 0.54 & na & na \\
\hline & & Low education & Middle-high education & Low education & Middle-high education & Low education & Middle-high education \\
\hline \multicolumn{2}{|l|}{ Third abortions } & $\mathrm{OR}^{\mathrm{a}}$ & $\mathrm{OR}^{\mathrm{a}}$ & $\mathrm{OR}^{\mathrm{a}}$ & $\mathrm{OR}^{\mathrm{a}}$ & $\mathrm{OR}^{\mathrm{a}}$ & $\mathrm{OR}^{\mathrm{a}}$ \\
\hline \multirow{6}{*}{ Time since last abortion } & $<6$ months & 1.00 & 1.00 & 1.00 & 1.00 & 1.00 & 1.00 \\
\hline & 6-12 months & $1.59^{*}$ & $1.70^{*}$ & $2.26^{* * *}$ & $1.71 * *$ & $1.89^{* * *}$ & $2.09^{* * *}$ \\
\hline & $1-2$ years & $2.08^{* * *}$ & $2.06^{* *}$ & $2.48^{* * *}$ & $1.92 * * *$ & 1.22 & $1.57^{*}$ \\
\hline & $2-4$ years & 1.48 & $1.61^{*}$ & $2.19^{* * * *}$ & $1.49^{* *}$ & 1.31 & 1.15 \\
\hline & 4-6 years & 0.98 & 1.19 & $1.67^{* *}$ & 1.11 & 0.97 & 0.94 \\
\hline & $\geq 6$ years & $0.65^{*}$ & 0.74 & 1.21 & 0.88 & 0.74 & $0.65^{*}$ \\
\hline \multirow[t]{4}{*}{ Parity } & $\bar{N}_{0}$ children & 1.00 & 1.00 & 1.00 & 1.00 & 1.00 & 1.00 \\
\hline & 1 & $1.52^{* * *}$ & 1.19 & $1.40^{* * *}$ & $1.41^{* * *}$ & $1.41^{* * *}$ & $1.35^{* *}$ \\
\hline & 2 & $1.63^{* * *}$ & $1.24^{*}$ & $1.64 * * *$ & $1.57 * * *$ & $1.98^{* * *}$ & $1.82 * * *$ \\
\hline & $\geq 3$ & $1.94 * * *$ & $1.61^{* * *}$ & $1.74 * * *$ & $1.99^{* * *}$ & $2.04 * * *$ & $2.51^{* * *}$ \\
\hline \multirow{4}{*}{ Union status } & Single & 1.00 & 1.00 & 1.00 & 1.00 & 1.00 & 1.00 \\
\hline & Married & $0.67^{* * *}$ & $0.65^{* * *}$ & $0.62^{* * *}$ & $0.47^{* * *}$ & $0.54 * * *$ & $0.39^{* * *}$ \\
\hline & Cohabiting & na & na & $0.68^{* * *}$ & $0.54^{* * *}$ & $0.63^{* * *}$ & $0.51 * * *$ \\
\hline & Divorced & 1.11 & $1.32 * *$ & 1.12 & 1.05 & 1.12 & 0.95 \\
\hline \multirow[t]{5}{*}{ Age } & $20-24$ & 1.00 & 1.00 & 1.00 & 1.00 & 1.00 & 1.00 \\
\hline & $25-29$ & 0.93 & 1.17 & 1.01 & 1.20 & 1.01 & 0.94 \\
\hline & $30-34$ & 0.86 & $1.32 *$ & $0.80^{*}$ & 1.13 & $0.55^{* * *}$ & $0.57 * * *$ \\
\hline & $35-39$ & $0.62 * * *$ & 0.88 & $0.48^{* * *}$ & $0.72^{* *}$ & na & na \\
\hline & $40+$ & $0.20^{* * *}$ & $0.43 * * *$ & $0.13^{* * *}$ & $0.19^{* * *}$ & na & na \\
\hline
\end{tabular}



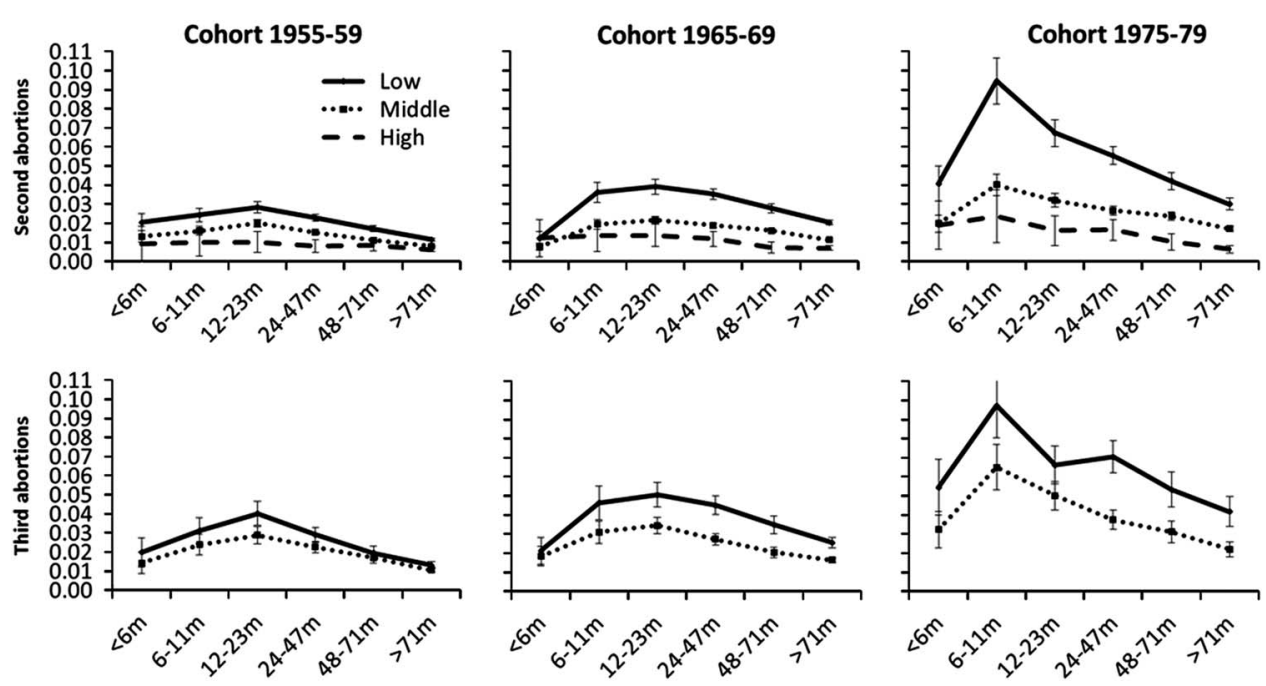

Fig. 1. Predicted probabilities of second and third abortions by time since previous abortion, education (low, middle, high) and cohort, adjusted for age, union status, parity, place of residence and nativity.

higher among women with low education in the latest cohort compared with women in this educational group in the earliest cohort.

Sensitivity analyses including only women aged 20-31 were conducted in order to make the exposure time the same for all cohorts. These analyses showed the interpretation of the results remained essentially the same and the educational differentials remained more marked for the later than the earlier cohorts. The risk of abortion peaked more clearly than in the models shown in Fig. 1 for 1950s and 1960s cohorts, and the risk of abortion for women with high parity was slightly higher than in Table 3 (results available on request).

\section{Discussion}

This study showed that the likelihood of repeat abortion was negatively associated with educational level and these differences increased over time. These results add to the literature, since previous research on the topic has not used a high-quality large-scale dataset like the one in this study, and thus the results have been inconclusive. Some studies found an association between low socioeconomic position and higher likelihood of repeat abortion (Jones et al., 2006; Das et al., 2009; Väisänen \& Jokela, 2010; Mentula et al., 2010; Makenzius et al., 2011), whereas others did not (Osler et al., 1997). Given that under-reporting of abortion is a common problem in all survey-based studies on abortion and that this problem is likely to be more severe for studies on repeat abortion, this paper provides a crucial addition to the reproductive health literature.

The study confirms that education is strongly associated with the likelihood of repeat abortion even in Finland, where a high proportion of the population has tertiary education (OECD, 2010), family planning services are available in all municipalities 
(Hemminki et al., 1997) and the population is relatively homogenous in its ethnic composition. For instance, between 1980 and 2010 less than 5\% of the population spoke a language that was not an official language (Finnish or Swedish) as their native language (Office Statistics of Finland, 2015). One concerning result was that the educational inequalities in the likelihood of repeat abortion changed from tiny in the 1950s cohort to clearly marked differences in the 1970s cohort. Possible reasons for these differences and means of rapid intervention are outlined below.

The lower likelihood of repeat abortion among highly educated women shows that it is possible to have relatively few women progressing onto their second or third abortion. The likelihood was largely independent of duration since last birth or abortion, relationship status and parity. Among other educational groups these characteristics mattered, which suggests that women with low and middle education more often use abortions to space and stop childbearing than women with high education. Perhaps women with high education benefit more from post-abortion contraceptive counselling than women with low education. This is supported by the finding that low educated women had high levels of risk shortly after a previous abortion and that on average the interval between abortions was longer for those with high education.

Varying quality of family planning care may explain part of the educational differences. In the mid-1990s, women with high socioeconomic status were more likely to use private family planning services, and thus had shorter waiting periods before appointments and more often received care from a specialist than women who used public sector services (Hemminki et al., 1997), which may lead to more timely and effective contraceptive use. As women with low education have lower income and they more often come from an immigrant background than women with high education, they may not have timely access to family planning services due to high out-of-pocket costs in private clinics and long waiting times in public clinics, lack of knowledge of these services, or both. New studies on the topic are needed to confirm this. In the meantime, the creation of high-quality family planning services easily accessible for all women is likely to be helpful in reducing the educational inequalities in the likelihood of repeat abortion.

Although the price of most commonly used contraceptives is less than $1 \%$ of annual mean income of women (Koistinen, 2008; Väestöliitto - Family Federation of Finland, 2012; Statistics Finland, 2013; University Pharmacy, 2014), the poorest women may struggle to pay for contraceptives. In addition, some municipalities introduced small fees for family planning service use in the 1990s (Kosunen, 2000), which may have impacted predominantly the poorest women. In France free contraceptives reduced the likelihood of repeat abortion, particularly among those with low income (Alouini et al., 2002). Providing free contraceptives is thus one possible intervention for reducing educational differences in unintended pregnancy and repeat abortion. Studies in many countries have found that promoting use of long-acting reversible contraception might be the most effective way forward (e.g. Heikinheimo et al., 2008; Ames \& Norman, 2012; Rose \& Lawton, 2012; Pohjoranta et al., 2015).

The increase in educational differences in later cohorts compared with the earlier ones was partly due to selection into education, as shown in Table 1: although it was still fairly common to have low education in the 1950s cohort, it became increasingly unusual in the later cohorts. Thus, women with low education have probably become a selected group, different from other women in other characteristics as well, which may partly 
explain why these women more often have repeat abortions than others. For instance, as having low education becomes less common, those without a graduate degree may have to accept less attractive jobs than those in earlier cohorts, when this was more common (Breen et al., 2009), leading to lower income and a more precarious position in the labour market. They differ from those with higher socioeconomic position in other aspects of health too, as shown by mortality differences by socioeconomic status, which have increased in the past decades in Finland (Mackenbach et al., 2003; Shkolnikov et al., 2011). Therefore the higher incidence of repeat abortion needs to be interpreted within the wider context of the lives of these women. They may not have the same resources as other women to access family planning or other health care services, or use contraceptives consistently and efficiently.

There were limitations in this study due to lack of information on variables not included in population registers and lack of detail due to ethics regulations. For instance, valuable information could have been gained by comparing women with repeat unintended births with women with repeat abortions, but pregnancy intentions were not known. Moreover, there was no information on contraceptive use although this is associated with the likelihood of abortion.

Despite the limitations, the results are robust due to the reliability of register data and provide new information. These results are of interest to researchers and policymakers in countries like Finland where family planning services do not receive much attention due to low average fertility and abortion levels. Inequalities in levels of unintended pregnancy are the key to understanding why some women have to rely on abortion more often than others.

\section{Acknowledgments}

The author thanks Professor Mike Murphy, Dr Tiziana Leone and Professor Mikko Myrskylä for their helpful comments, and Professor Mika Gissler and Dr Markus Jokela for their expertise help in obtaining the dataset. The author was supported by the Economic and Social Research Council (grant number ES/J00070/1). The author is grateful to Statistics Finland and the National Institute of Health and Welfare for their permission (TK53-162-11 and THL/173/5.05.00/2011 respectively) to use these data.

\section{References}

Alouini, S., Uzan, M., Méningaud, J. P. \& Hervé, C. (2002) Knowledge about contraception in women undergoing repeat voluntary abortions, and means of prevention. European Journal of Obstetrics \& Gynecology and Reproductive Biology 104, 43-48.

Ames, C. M. \& Norman, W. V. (2012) Preventing repeat abortion in Canada: is the immediate insertion of intrauterine devices postabortion a cost-effective option associated with fewer repeat abortions? Contraception 85, 51-55.

Breen, R., Luijkx, R., Muller, W. \& Pollak, R. (2009) Nonpersistent inequality in educational attainment: evidence from eight European countries. American Journal of Sociology 114, 1475-1521.

Cleland, K., Peipert, J. F., Westhoff, C., Spear, S. \& Trussell, J. (2011) Family planning as a costsaving preventive health service. New England Journal of Medicine 364, e37.

Das, S., Adegbenro, A., Ray, S. \& Amu, O. (2009) Repeat abortion: facts and issues. Journal of Family Planning and Reproductive Health Care 35, 93-95. 
Frost, J. J., Sonfield, A., Zolna, M. R. \& Finer, L. B. (2014) Return on investment: a fuller assessment of the benefits and cost savings of the US publicly funded family planning program. US publicly funded family planning program. Milbank Quarterly 92, 696-749.

Gissler, M., Ulander, V-M., Hemminki, E. \& Rasimus, A. (1996) Declining induced abortion rate in Finland: data quality of the Finnish Abortion Register. International Journal of Epidemiology 25, 376-380.

Heikinheimo, O., Gissler, M. \& Suhonen, S. (2008) Age, parity, history of abortion and contraceptive choices affect the risk of repeat abortion. Contraception 78, 149-154.

Heino, A., Gissler, M. \& Soimula, A. (2011) Induced Abortions 2010. National Institute of Health and Welfare, Helsinki.

Hemminki, E., Sihvo, S., Koponen, P. \& Kosunen, E. (1997) Quality of contraceptive services in Finland. Quality and Safety in Health Care 6, 62-68.

Jones, R. K. \& Kost, K. (2007) Underreporting of induced and spontaneous abortion in the United States: an analysis of the 2002 National Survey of Family Growth. Studies in Family Planning 38, 187-197.

Jones, R. K., Singh, S., Finer, L. B. \& Frohwirth, L. (2006) Repeat Abortion in the United States. Guttmacher Institute, New York.

Knudsen, L. B., Gissler, M., Bender, S. S., Hedberg, C., Ollendorff, U., Sundström, K. et al. (2003) Induced abortion in the Nordic countries: special emphasis on young women. Acta Obstetricia et Gynecologica Scandinavica 82, 257-268.

Koistinen, M. (2008) The Price of Contraceptives Varies from Dozens to Hundreds of Euros per Year [Ehkäisyn hinta vaihtelee kympeistä satasiin vuodessa]. Helsingin Sanomat.

Kontula, O. (2010) The evolution of sex education and students' sexual knowledge in Finland in the 2000s. Sex Education 10, 373-386.

Kosunen, E. (2000) Family planning services. In Lottes, I. \& Kontula, O. (eds) New Views on Sexual Health - The Case of Finland. Väestöliitto, Helsinki, pp. 70-84.

Levels, M., Sluiter, R. \& Need, A. (2014) A review of abortion laws in Western-European countries. A cross-national comparison of legal developments between 1960 and 2010. Health Policy 118, 95-104.

Mackenbach, J. P., Bos, V., Andersen, O., Cardano, M., Costa, G., Harding, S. et al. (2003) Widening socioeconomic inequalities in mortality in six Western European countries. International Journal of Epidemiology 32, 830-837.

Makenzius, M., Tydén, T., Darj, E. \& Larsson, M. (2011) Repeat induced abortion - a matter of individual behaviour or societal factors? A cross-sectional study among Swedish women. European Journal of Contraception \& Reproductive Health Care 16, 369-377.

Mentula, M. J., Niinimäki, M., Suhonen, S., Hemminki, E., Gissler, M. \& Heikinheimo, O. (2010) Young age and termination of pregnancy during the second trimester are risk factors for repeat second-trimester abortion. American Journal of Obstetrics and Gynecology 203, 107.e1-107.e7.

Niinimäki, M., Pouta, A., Bloigu, A., Gissler, M., Hemminki, E., Suhonen, S. \& Heikinheimo, O. (2009) Frequency and risk factors for repeat abortions after surgical compared with medical termination of pregnancy. Obstetrics and Gynecology 113, 845-852.

OECD (2010) How many young people graduate from tertiary education? In Highlights from Education at a Glance 2010. OECD Publishing, Paris, pp. 18-19.

Official Statistics of Finland (2015) Population Structure [e-publication]. Statistics Finland, Helsinki. URL: http://www.stat.fi/til/vaerak/index_en.html (accessed 9th October 2015).

Osler, M., David, H. P. \& Morgall, J. M. (1997) Multiple induced abortions: Danish experience. Patient Education and Counseling 31, 83-89.

Pohjoranta, E., Mentula, M., Gissler, M., Suhonen, S. \& Heikinheimo, O. (2015) Provision of intrauterine contraception in association with first trimester induced abortion reduces the need 
of repeat abortion: first-year results of a randomised controlled trial. Human Reproduction doi: 10.1093/humrep/dev233.

Rose, S. B. \& Lawton, B. A. (2012) Impact of long-acting reversible contraception on return for repeat abortion. American Journal of Obstetrics and Gynecology 206, 37.e1-37.e6.

Rose, S. B., Stanley, J. \& Lawton, B. A. (2015) Time to second abortion or continued pregnancy following a first abortion: a retrospective cohort study. Human Reproduction 30, 214-221.

Shkolnikov, V. M., Andreev, E. M., Jdanov, D. A., Jasilionis, D., Kravdal, O., Vågerö, D. \& Valkonen, T. (2011) Increasing absolute mortality disparities by education in Finland, Norway and Sweden, 1971-2000. Journal of Epidemiology and Community Health 66, 372-378.

Statistics Finland (2013) Income and Consumption. Statistics Finland, Helsinki. URL: http://www. stat.fi/tup/suoluk/suoluk_tulot_en.html\#recipients (accessed 29th June 2015).

Stone, N. \& Ingham, R. (2011) Who presents more than once? Repeat abortion among women in Britain. Journal of Family Planning and Reproductive Health Care 37, 209-215.

University Pharmacy (2014) Online Pharmacy [Verkkoapteekki - Yliopiston Apteekki]. URL: http://www.yliopistonapteekki.fi/fi/apteekkipalvelut/pages/english.aspx (accessed 29th January 2014).

Väestöliitto - Family Federation of Finland (2012) IUD [Kierukka]. URL: http://www.vaestoliitto. fi/seksuaalisuus/tietoa-seksuaalisuudesta/aikuiset/seksuaalisuuden_suloja_ja_seksin/raskauden_ ehkaisy/kierukka/ (accessed 29th January 2014).

Väisänen, H. (2015) The association between education and induced abortion for three cohorts of adults in Finland. Population Studies 69, 373-388.

Väisänen, H. \& Jokela, M. (2010) Fertility after induced abortion: a register-based study in Finland 2000-2008. Finnish Yearbook of Population Research XLV, 25-44.

Väisänen, H. \& Murphy, M. (2014) social inequalities in teenage fertility outcomes: childbearing and abortion trends of three birth cohorts in Finland. Perspectives on Sexual and Reproductive Health 46, 109-116.

Vikat, A. (2004) Women's labor force attachment and childbearing in Finland. Demographic Research 3 (Special Issue), 177-212.

Williams, R. (2012) Using the margins command to estimate and interpret adjusted predictions and marginal effects. Stata Journal 12, 308-331. 